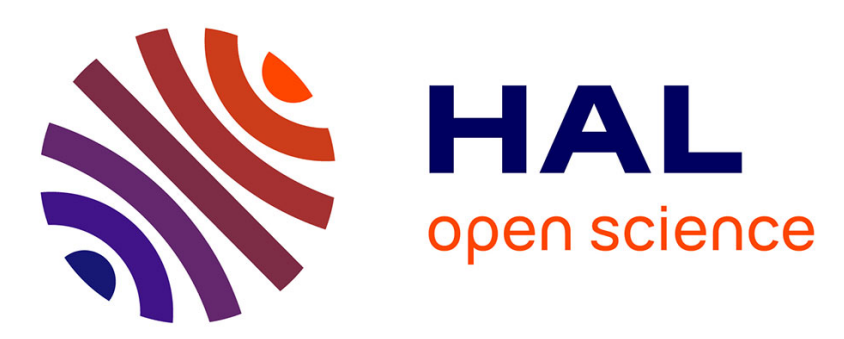

\title{
Kinematic behaviour modeling of the axes of a machining center in high speed milling
}

Bassem Gassara, Gilles Dessein, Maher Baili, Moncef Hbaieb, Wassila Bouzid

\section{To cite this version:}

Bassem Gassara, Gilles Dessein, Maher Baili, Moncef Hbaieb, Wassila Bouzid. Kinematic behaviour modeling of the axes of a machining center in high speed milling. Advanced Materials Research, 2013, vol. 698 , pp. 39-48. hal-00831107

\section{HAL Id: hal-00831107 https://hal.science/hal-00831107}

Submitted on 6 Jun 2013

HAL is a multi-disciplinary open access archive for the deposit and dissemination of scientific research documents, whether they are published or not. The documents may come from teaching and research institutions in France or abroad, or from public or private research centers.
L'archive ouverte pluridisciplinaire HAL, est destinée au dépôt et à la diffusion de documents scientifiques de niveau recherche, publiés ou non, émanant des établissements d'enseignement et de recherche français ou étrangers, des laboratoires publics ou privés. 


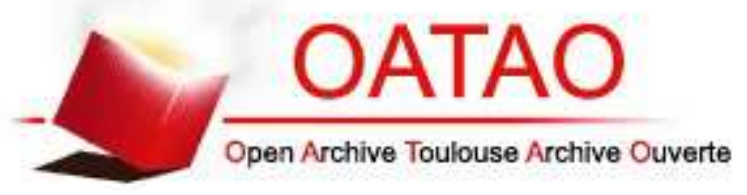

\section{Open Archive Toulouse Archive Ouverte (OATAO)}

OATAO is an open access repository that collects the work of Toulouse researchers and makes it freely available over the web where possible.

This is an author-deposited version published in: http://oatao.univ-toulouse.fr/ Eprints ID: 8581

To link to this article: DOI:10.4028/www.scientific.net/AMR.698.39 http://www.ttp.net/1022-6680.html

\section{To cite this version:}

Gassara, Bassem and Dessein, Gilles and Baili, Maher and Hbaieb, Moncef and Bouzid, Wassila Kinematic behaviour modeling of the axes of a machining center in high speed milling. (2013) Advanced Materials Research, vol. 698 . pp. 39-48. ISSN 1022-6680

Any correspondence concerning this service should be sent to the repository administrator: staff-oatao@inp-toulouse.fr 


\title{
Kinematic behaviour modeling of the axes of a machining center in high speed milling
}

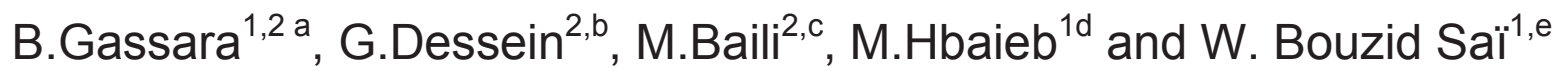 \\ ${ }^{1}$ Unité de Génie de Production Mécanique et Matériaux, ENIS, route Soukra Km 3,5-B.P. 1173- \\ 3038 Sfax-Tunisie \\ ${ }^{2}$ Université de Toulouse ; INPT/ENIT ; Laboratoire Génie de Production; 47 avenue d'Azereix, BP \\ 1629, F-65016 Tarbes \\ Cedex, France \\ a bassem.gassara@enit.fr, bgilles.dessein@enit.fr, ${ }^{\text {cm }}$ maher.baili@enit.fr, ${ }^{d}$ mhbaeib@yahoo.fr, \\ ewassilabouzid@yahoo.fr,
}

Keywords: high speed milling, discontinuities in tangency or curvature, Kinematic behaviour, cycle time.

\begin{abstract}
In the context of high speed milling "HSM", the feed rate does not always reach the programmed value during the machining process which implies an increase of machining time and non compliance with the programmed feed rate. This phenomenon leads to productivity issues and an underestimation of the cost of machining for the industry.

The aim of this study is to identify the kinematic behaviour of the machine tool during any type of discontinuity between linear and circular contours in different combination by taking into account the specific machining tolerances. In order to achieve this, a model of the law of the axes motion and the actual trajectory at discontinuities is necessary. This method is based on the subdividing of the trajectory into elementary geometries according to the type of interpolation (circular or linear). The proposed method can estimate the cycle time with a maximum error of $5 \%$ between the actual and the prediction cycle time.

Finally, an experimental study was carried out on a high speed machine. It is based on elementary tests in order to analyze the axes behavior during any type of discontinuity and to validate the developed models.
\end{abstract}

\section{Introduction}

The growing competition in the market continues to evolve the standards of quality. The requirements to reduce time and costs are always higher. This gave birth to new processes and production techniques including the High Speed Milling "HSM". This machining process is the most used method in industry and where the cutting speed can reach values of five to ten times higher than those used in conventional machining [1]. However, the important feed rates and accelerations of the axes solicit the structure of the machine, its digital servo drives control and its numerical control. The response of the machine in these conditions is different from imposed feed rate and trajectory. For example, the actual machining time is often very high compared to the time estimated by the CAM software. Indeed, the feed rate does not always reach the programmed speed during a machining process $[2,3,4]$.

The generated tool path can be expressed using linear and circular interpolations. At points where different interpolations meet, there is often a discontinuity in curvature or in tangency. At the points of discontinuity, the movement of the axes slows down in order to respect the maximum values of acceleration and Jerk for each axis which results in an increase in the cycle time.

In this context, several works have been interested to adapt the tool path to rapid piloting of the machine. So, two models for smoothing the trajectory were distinguished. The first is meant to approximate the trajectory by a polynomial function [5]. The second is based on the addition of a 
circle arc to the crossing of discontinuities. The radius of this arc is determined considering a discontinuity between two linear interpolations $[6,7]$.

The objective of this study is to determine a model to identify the kinematic behaviour of the axes of a machining center in HSM during any type of discontinuity between linear and circular contours in different combination, while respecting an imposed error value on the path.

In the first part, a modeling of the feed rate and a geometric of continuity in tangency are presented. Then, in a second part, the model of calculation time is proposed. Finally, an experimental study was carried out on a HSM machine in order to validate the developed models.

\section{Kinematic behaviour evaluation of the axes of a machine center}

The evaluation of the kinematic behaviour of the axes requires modeling of the feed rate and the tool path in the transition of the discontinuity.

Feed rate modeling. Based on the work of Dugas, Erkorkmaz et al. and Gassara et al. [6, 8, 9], the variation of the feed rate for linear and circular interpolation is modeled by taking into account the limitations of the machine and the geometry of the existent trajectory. Fig. 1a describes the correspondence between the tool path and the profile of the feed rate. With $V_{c i r}, V_{f p r o g}, V_{f c}$ and $\mathrm{R}$ are respectively, the feed rate in a circular interpolation, the programmed feed rate, the feed rate at a discontinuity crossing and the radius of interpolation
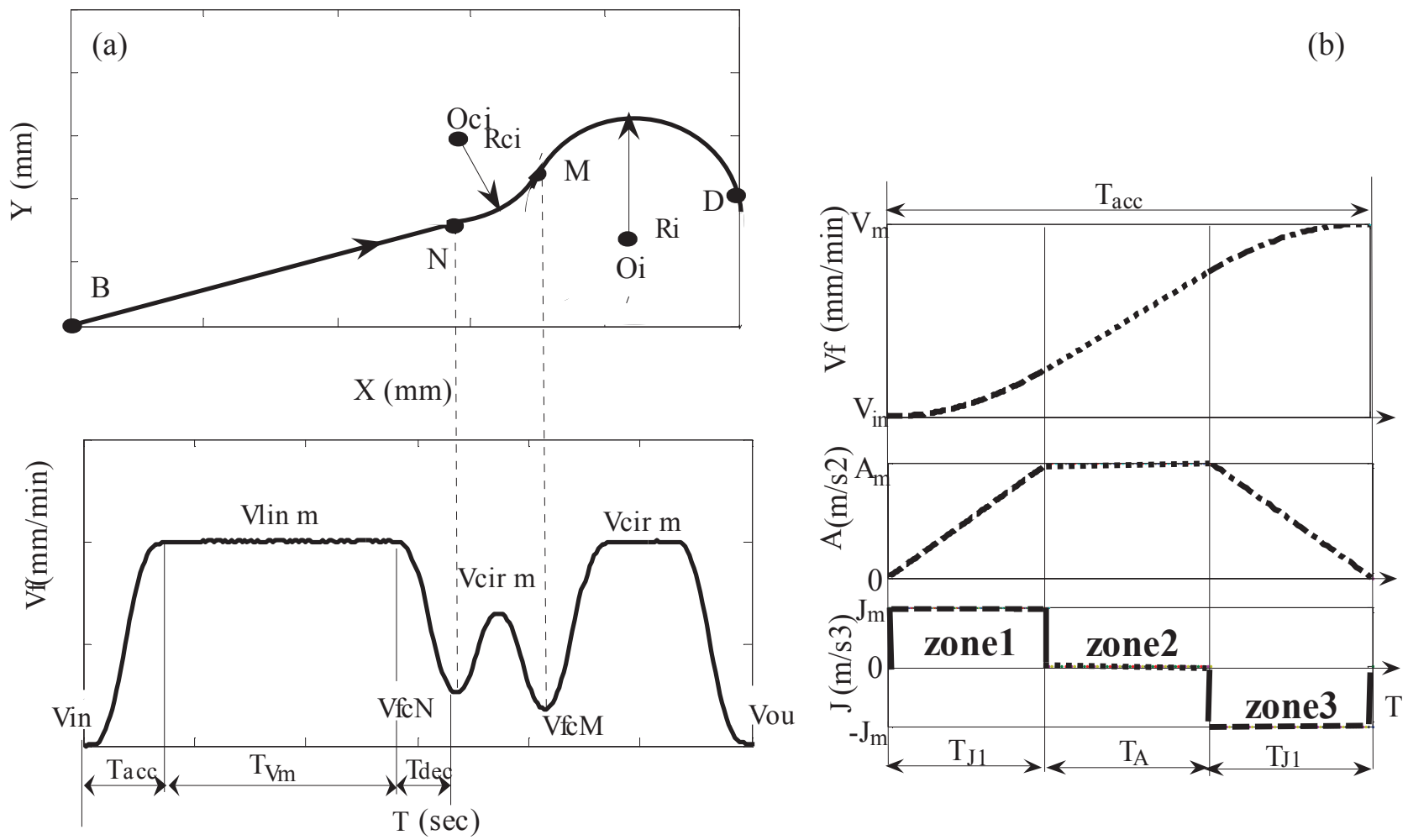

Fig. 1: Feed rate profile for a tool path (a) Various acceleration phases (b)

Modeling the law of the axes motion. In this modeling, a constant jerk value is considered (trapezoidal acceleration profile, Fig. 1b). Each axis of a machine is characterized by its kinematic maximum capacities. A given axis has a maximum feed rate $V_{m}$, a maximum acceleration $A_{m}$ and a maximum jerk $J_{m}$. The movement law of feed rate is divided into three phases (Fig. 1a). During the first phase, the feed rate increases and reaches the stationary value. In this phase, the tangential acceleration increases until reaching its maximum value. The acceleration ramp depends on the maximum reachable jerk of the machine. Then, in the second phase, the acceleration decreases linearly to reach a null value. So, the maximum feed rate is reached. Finally the third phase is totally symmetrical to the first phase with a deceleration allowing a reduction of the feed rate. 
For motion along the tool path, the acceleration phase is composed of 3 zones (Fig. 1b). The deceleration time is given by the following expression:

$T_{\text {dec }}=T_{A}+2 T_{J 1}$

Where: $T_{J I}$ and $T_{A}$ are respectively, the time when the feed rate is controlled by a maximum value of the jerk and the time when the feed rate is controlled by a maximum value of acceleration.

Feed rate for a linear interpolation. In linear interpolation, the limitation of the feed rate is essentially due to the cycle time interpolation of the numerical control unit (NCU), the programmed feed rate and the block length.

The feed rate authorized by the NCU $\left(V_{\text {lin } m}\right)$ is given by:

$V_{\text {lin } m}=\min \left(V_{\text {tcy }}, V_{L_{b}}, V_{\text {fprog }}\right)$

With: $V_{t c y}=\frac{L}{T_{c y}}$

$V_{L b}$ is a function of the block length and the machine kinematic parameters (jerk and acceleration). This limitation will take place when the sum of the length of acceleration and deceleration is bigger than the length of a block $L_{b}$.

Feed rate for circular interpolation. For circular interpolation, the feed rate is limited by three kinematic parameters of the axes (acceleration, jerk and maximum feed rate) and the radius value of a circular interpolation $\mathrm{R}_{\mathrm{i}}$.

The feed rate $\left(V_{\text {cir } m}\right)$ authorized by the NCU is given by:

$V_{\text {cir } m}=\min \left(V_{\text {fprog }} ; V_{L b} ; V_{J} ; V_{A m} ; V_{\text {tcy }}\right)$

The feed rate $V_{A m}$ corresponding to the limitation of the acceleration is given by [6]:

$V_{A m}=\sqrt{R_{i} A_{m}}$

The feed rate $V_{J}$ corresponding to the limitation of jerk is given by [6]:

$V_{J}=\sqrt[3]{J_{m} R_{i}^{2}}$

In circular interpolation, the programmed feed rate $V_{f p r o g}$ depends on the nature of the circular shape machined: convex or concave. For a concave circular shape, we can use on Sinumerik 840D NCU correction of the feed rate by using the normal correction profile with constant feed (CFIN ${ }^{1}$ on NCU Sinumerik 840D) [10]. In this case, the programmed feed rate becomes:

$V_{\text {fprog }}^{\prime}=\frac{R_{p}-R_{\text {tool }}}{R_{p}} V_{\text {fprog }}$

$R_{p}$ is the workpiece curvature radius and $R_{\text {toul }}$ is the tool radius.

Feed rate of crossing on a continuity in tangency. At a tangency of continuity (discontinuity in curvature), the NCU slows down the movement of the axes in order to respect the maximum acceleration and jerk values for each axis.

- Continuity in tangency between circular and linear interpolation (point $\mathrm{N}$ as shown in Fig. 1a) [7]: $V_{f c N}=\sqrt{R_{C i} C}$ et $C=J_{m} \delta t$

- Continuity in tangency between two circular interpolations (point M as shown in Fig. 1a):

$V_{f c M}=\sqrt{\frac{R_{i} R_{C i} J_{m} \delta t}{R_{i}+R_{C i}}}$

\footnotetext{
${ }^{1}$ Instruction of correction the feed at inside curvature of Sinumerik language
} 
Geometric modeling of continuities in tangency. The path generated by the CAM software/Mastercam is discretized into several elementary blocks according to the type of interpolation (linear and circular). A discontinuity in curvature or tangency at points where different blocks meet tends to slow down the feed rate and thereafter increasing the cycle time. The rate of change depends on the orientation angle $\gamma_{i}$ between two consecutive interpolations (Fig. 2). With $i$ Varies from 1 to $\mathrm{n}$ and $\mathrm{n}$ is the total number of block.

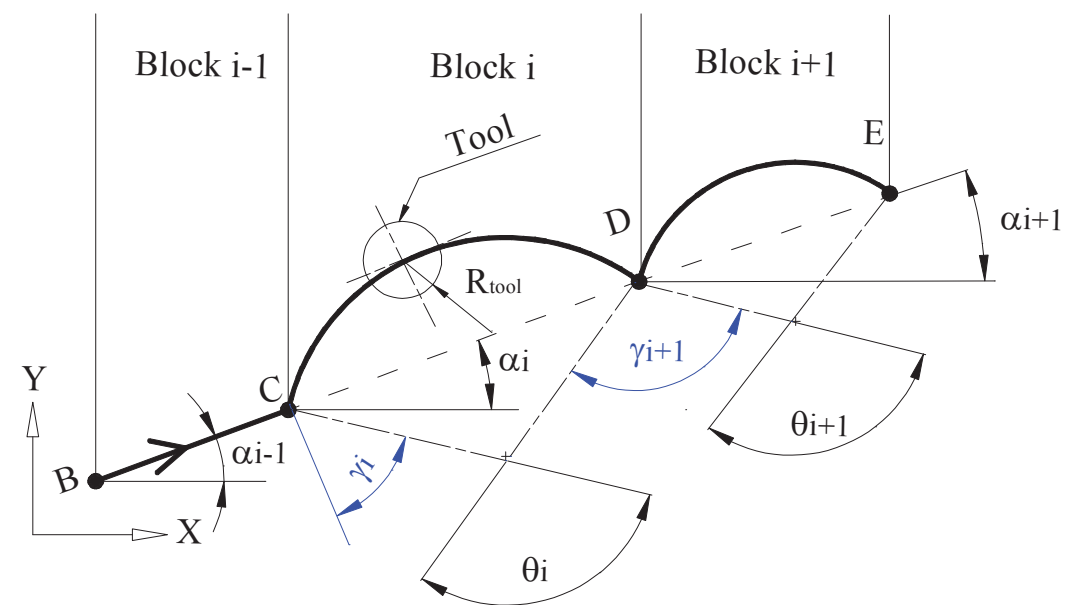

Fig. 2: Discretization of the tool center path

The equation of the orientation angle $\gamma_{i}$ for the tool path is depended on the type of interpolation (linear or circular).

The equations of the orientation angle $\gamma_{i}$ for linear and circular contours in different combinations are presented in table 1.

Table 1: Calculation of the orientation angle according to the type of interpolation

\begin{tabular}{cccc}
$\begin{array}{c}\text { Connection } \\
\text { Between }\end{array}$ & Equation of $\gamma_{i}$ & $\begin{array}{c}\text { Connection } \\
\text { Between }\end{array}$ & Equation of $\gamma \mathrm{i}$ \\
\hline G1G1 & $\alpha_{i}-\alpha_{i-1}$ & G2G3 & $\frac{\theta_{i-1}}{2}-\frac{\theta_{i}}{2}-\alpha_{i-1}+\alpha_{i}$ \\
G1G3 & $\frac{\theta_{i}}{2}+\alpha_{i-1}-\alpha_{i}$ & G3G2 & $\frac{\theta_{i}}{2}-\frac{\theta_{i-1}}{2}-\alpha_{i-1}+\alpha_{i}$ \\
G3G1 & $\frac{\theta_{i-1}}{2}+\alpha_{i-1}-\alpha_{i}$ & G2G2 & $\frac{\theta_{i-1}}{2}+\frac{\theta_{i}}{2}-\alpha_{i-1}+\alpha_{i}$ \\
G1G2 & $\frac{\theta_{i}}{2}-\alpha_{i-1}+\alpha_{i}$ & G3G3 & $\frac{\theta_{i-1}}{2}+\frac{\theta_{i}}{2}+\alpha_{i-1}-\alpha_{i}$ \\
G2G1 & $\frac{\theta_{i-1}}{2}-\alpha_{i-1}+\alpha_{i}$ & & \\
\hline
\end{tabular}

From equations presented in table 1, we can distinguish two types of discontinuities in the path according to the value of $\gamma_{i}$. For a discontinuity in curvature (D.c.) $\gamma_{i}=0^{\circ}$, there is a continuity in feed rate. For a discontinuity in tangency ((D.t.) $0^{\circ}<\gamma_{i}<180^{\circ}$, there is no continuity in feed rate.

In the case of the linear-circular interpolation, the tool path is represented by a linear contour (BC) and a circular contour (CD: radius $\mathrm{R}_{\mathrm{i}}$ and center $\mathrm{O}_{\mathrm{i}}$ ) (as shown in Fig. 3).

The coordinate $X_{C}$ is given by:

$X_{C}=\frac{\cos \alpha_{i-1}}{\sqrt{\left(X_{C}-X_{B}\right)^{2}+\left(Y_{C}-Y_{B}\right)^{2}}}+X_{B}$

The coordinates of point $\mathrm{D}$ are given by: 


$$
X_{D}=2 R \sin \frac{\theta_{i}}{2} \cos \alpha_{i}+X_{C} \quad Y_{D}=2 R \sin \frac{\theta_{i}}{2} \sin \alpha_{i}+Y_{C}
$$

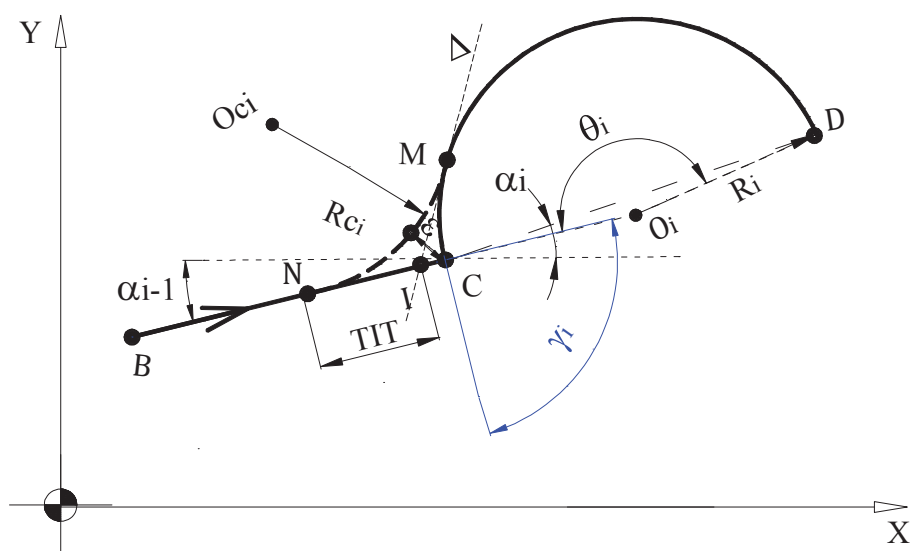

Fig. 3: Elementary path

The tool path presents a discontinuity in tangency located at the point $\mathrm{C}$ (as shown in fig 3). This discontinuity in tangency has been replaced by discontinuity in curvature by adding an arc with a center $\mathrm{O}_{\mathrm{ci}}$ and with a fillet radius $\mathrm{R}_{\mathrm{ci}}$.

Firstly, the angles $\theta_{\mathrm{i}}$ and $\alpha_{\mathrm{i}}$ are determined using Eq. 9 and Eq. 10. Then, the angle $\gamma_{\mathrm{i}}$ is calculated. The fillet radius $R_{c i}$, which depends on the imposed error $\varepsilon$, is calculated by:

$$
\left\{\begin{array}{l}
\left(X_{C}-X_{O_{c i}}\right)^{2}+\left(Y_{C}-Y_{O_{c i}}\right)^{2}=\left(\varepsilon+R_{c i}\right)^{2} \\
\frac{\left|\frac{Y_{C}-Y_{B}}{X_{C}-X_{B}} X_{O_{c i}}-Y_{O_{c i}}+\frac{Y_{B} X_{C}-Y_{C} X_{B}}{X_{C}-X_{B}}\right|}{\sqrt{1+\left(\frac{Y_{C}-Y_{B}}{X_{C}-X_{B}}\right)^{2}}}=R_{c i} \\
\left(X_{O_{i}}-X_{O_{c i}}\right)^{2}+\left(Y_{O_{i}}-Y_{O_{c i}}\right)^{2}=\left(R_{c i}+R_{i}\right)^{2}
\end{array}\right.
$$

The fillet radius $R_{c i}$, which depends on the imposed value of $\mathrm{TIT}^{2}$, is calculated by:

$$
\left\{\begin{array}{l}
T I T^{2}=\left(X_{M}-X_{I}\right)^{2}+\left(Y_{M}-Y_{I}\right)^{2} \\
T I T^{2}+R_{i}^{2}=\left(X_{O i}-X_{I}\right)^{2}+\left(Y_{O i}-Y_{I}\right)^{2} \\
\left(X_{O c i}-X_{O i}\right)\left(X_{M}-X_{O i}\right)+\left(Y_{O c i}-Y_{O i}\right)\left(X_{M}-X_{O i}\right)=0 \\
\frac{Y_{C}-Y_{B}}{X_{C}-X_{B}}-Y_{I}+\frac{Y_{B} X_{C}-Y_{C} X_{B}}{X_{C}-X_{B}}=0 \\
R_{c i}=\sqrt{\left(X_{M}-X_{O c i}\right)^{2}+\left(Y_{M}-Y_{O c i}\right)^{2}}
\end{array}\right.
$$

${ }^{2}$ The distance which the rounding block may begin 
The machine slowed at the discontinuities in tangency [4, 6, 7]. At this type of discontinuities, the NCU may authorize an advance speed not null if there is an error $\varepsilon$ imposed on the trajectory tracking (functional tolerance imposed on part design). In this case, a circular arc is created according to the imposed error $\varepsilon$ and the angle of orientation $\gamma_{\mathrm{i}}$. To insert the radius of connection at the discontinuities, the rounding function G641 integrated into the NCU and the modal rounding function of $\mathrm{RND}^{3}$ have to be used. For the first, the connection radius value depends on the distance from which or for which the block transition is rounded (TIT). Therefore, the distance must be specified with ADIS function. For the second, the connection radius between the blocks is inserted into the NC programs.

\section{Cycle time modeling}

The model developed above allows us to determinate the cycle time $T_{c}$ taking into account the geometry of the trajectory and the behaviour of the machine.

The cycle time is defined by the following expression:

$T_{c}=\sum_{i=1}^{n}\left(T_{V_{\mathrm{m}}}(i)+T_{a c c}(i)+T_{d e c}(i)\right)$

With: $i, T_{V m}, T_{a c c}$ and $T_{d e c}$ are respectively, the number of elementary interpolation, the cycle time using a maximum feed rate, the acceleration time and the deceleration time.

The different steps to determine the evolution of the feed rate and the cycle time $T_{c}$ are as follows:

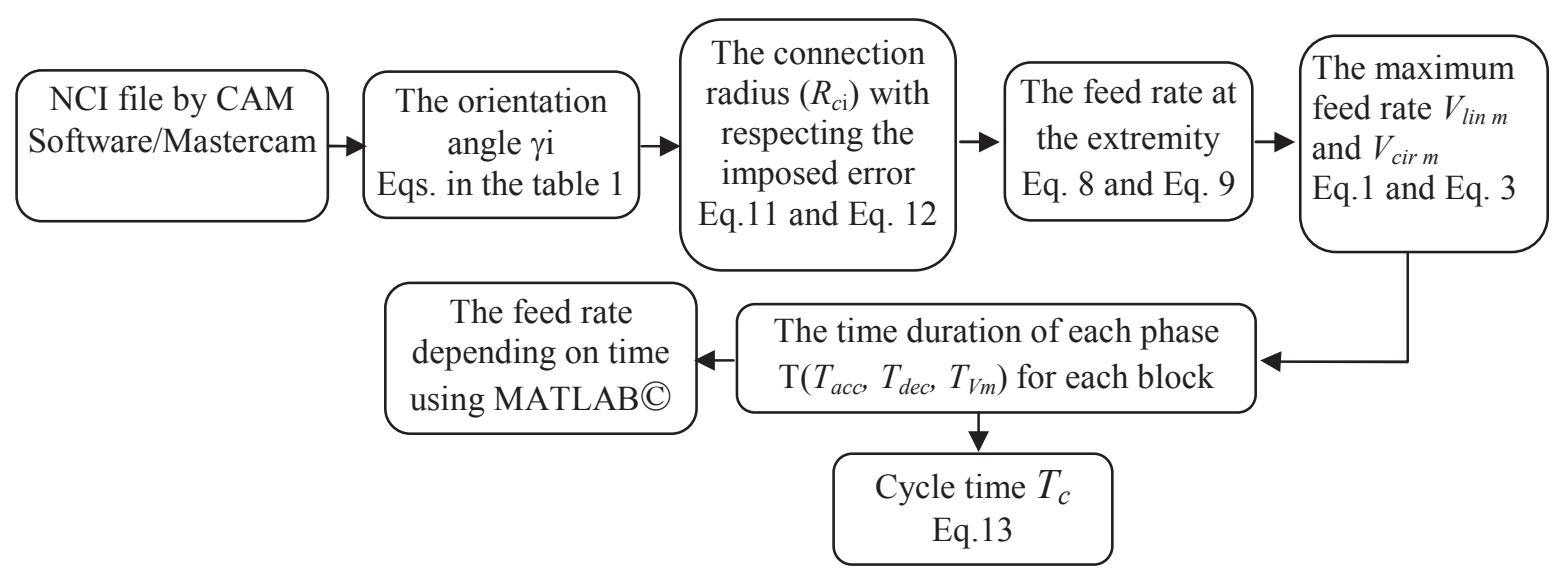

Fig. 4: Modeling steps

\section{Results and Discussion}

Based on this study, the impact of the imposed error value on the cycle time, according to the calculation of the feed rate evolution during motion along the tool path can be determined. To validate this study, two tests are performed on a high speed 3-axis machining center with a Sinumerik 840D NCU [10]. The first test enables to determine influence of tool path geometry on the feed rate. The second permits to study the impact of the imposed error value $\varepsilon$ on the cycle time. The characteristics of the machine are presented in the following table (Table 2).

Table 2: Characteristics of the machining center HURON KX-10

\begin{tabular}{|ll|}
\hline \multicolumn{2}{|c|}{ Huron KX10 } \\
\hline \hline Spindle speed & 100 à $24000 \mathrm{tr} / \mathrm{min}$ \\
Maximum feed rate & $30 \mathrm{~m} / \mathrm{min}$ \\
Maximum acceleration & $3 \mathrm{~m} / \mathrm{s}^{2}$ \\
maximum jerk & $50 \mathrm{~m} / \mathrm{s}^{3}$ \\
\hline
\end{tabular}

\footnotetext{
${ }^{3}$ Instruction of rounding the corner of the contour of Sinumerik language
} 
Influence of tool path geometry. To determine the influence of tool path geometry on the feed rate, the circular-linear interpolation for different orientation angles $\gamma_{\mathrm{i}}$ is considered. The theoretical and experimental feed rate profiles are superimposed on Fig. 5. In this case, the discontinuity in tangency is removed by the addition of a circle arc which is a function of TIT (by using the function G641).

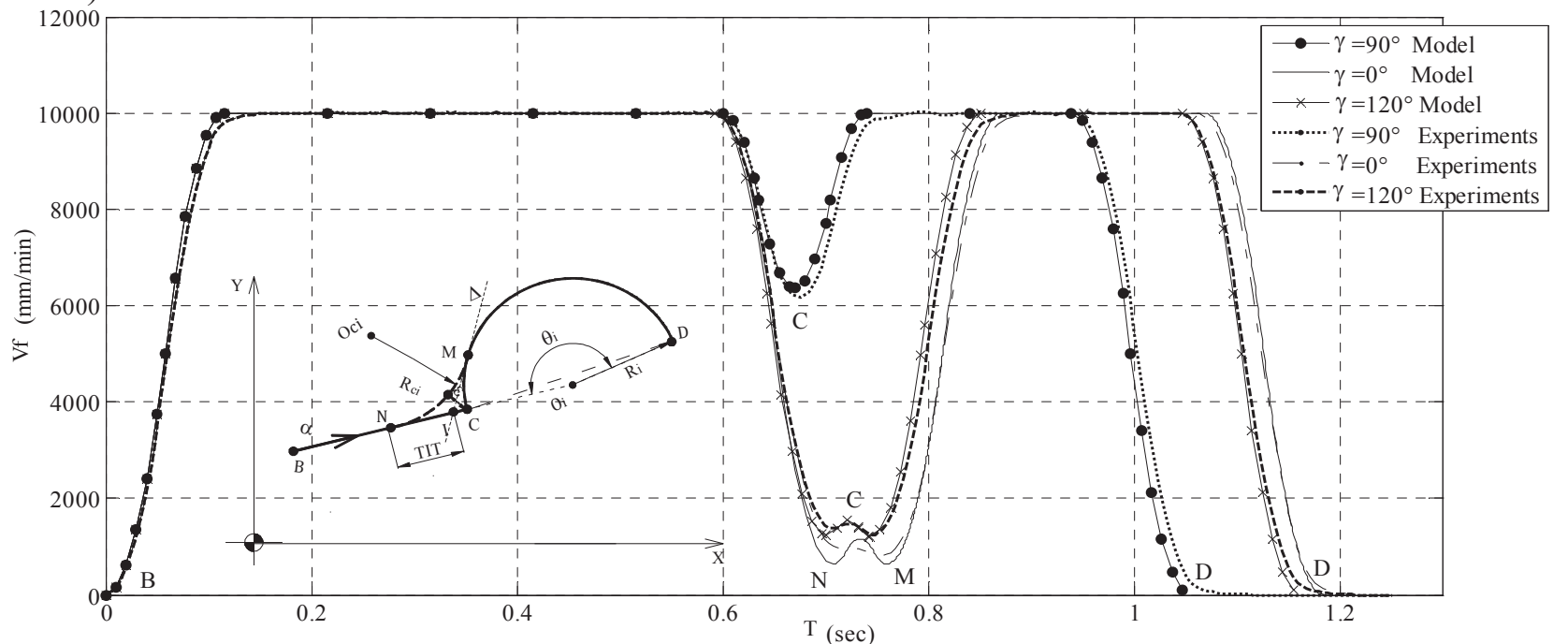

Fig. 5: Theoretical and experimental feed rate profiles for different values of $\gamma \mathrm{i}$; TIT $=0,5 \mathrm{~mm}$;

$$
\mathrm{BC}=100 \mathrm{~mm} \text { and } \mathrm{Ri}=50 \mathrm{~mm}
$$

The feed rate at a discontinuity crossing (Fig. 5) is maximum for an angle $\gamma_{i}=90$ (curvature discontinuity), then it decreases for other values of the angle $\gamma_{i}\left(0^{\circ}\right.$ et $\left.120^{\circ}\right)$ corresponding to a discontinuity in tangency.

Impact of the imposed error value on the cycle time. To determine the impact of the imposed error value $\varepsilon$ on the cycle time, the tool path shown in Fig. 6 is modified by adding arcs at the discontinuities located at points $\mathrm{C}, \mathrm{D}$ and $\mathrm{G}$ with different error values (detailed on table 3 ). This tool path is composed of five blocks; i varies from 1 to 5 .

These tests were developed in the experimental and theoretical studies.

Table 3. Geometry of the trajectory for different tests

\begin{tabular}{|c|c|c|c|c|c|c|}
\hline \multicolumn{2}{|c|}{ Error $\varepsilon[\mathrm{mm}]$} & 0.03 & 0.1 & 0.3 & 0.6 & 1 \\
\hline \hline Point C & $\mathrm{R}_{\mathrm{C} 1}[\mathrm{~mm}]$ & 0.27 & 0.91 & 2.99 & 6.89 & 14.11 \\
Point D & $\mathrm{R}_{\mathrm{C} 2}[\mathrm{~mm}]$ & 0.04 & 0.13 & 0.41 & 0.91 & 1.77 \\
Point $\mathrm{G}$ & $\mathrm{R}_{\mathrm{C} 5}[\mathrm{~mm}]$ & 0.89 & 3.31 & 14.08 & 55.21 & 436 \\
\hline
\end{tabular}

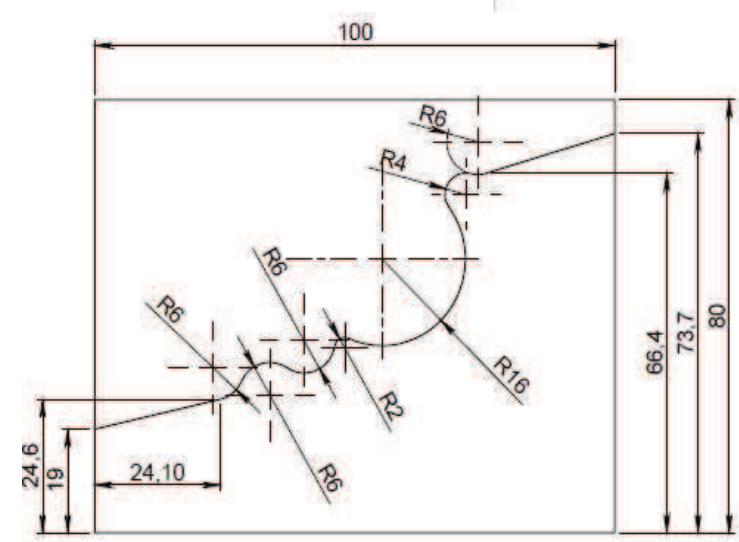

Test part

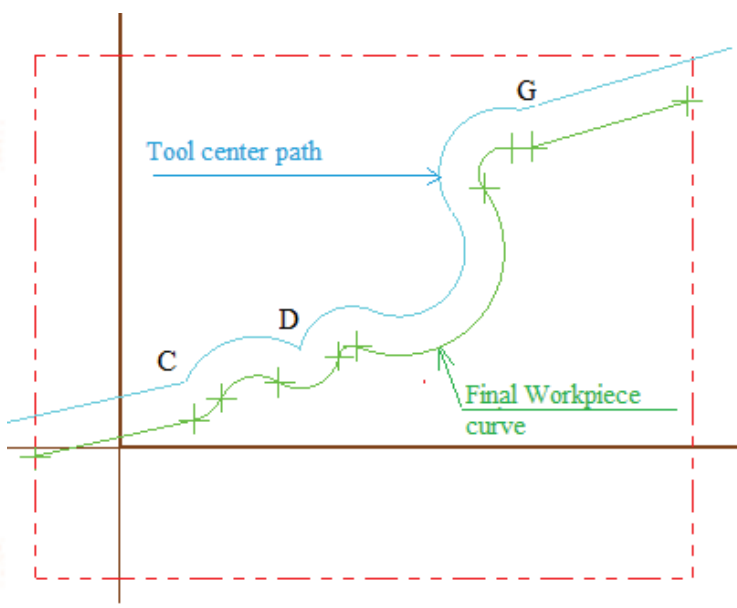

Machining simulation 


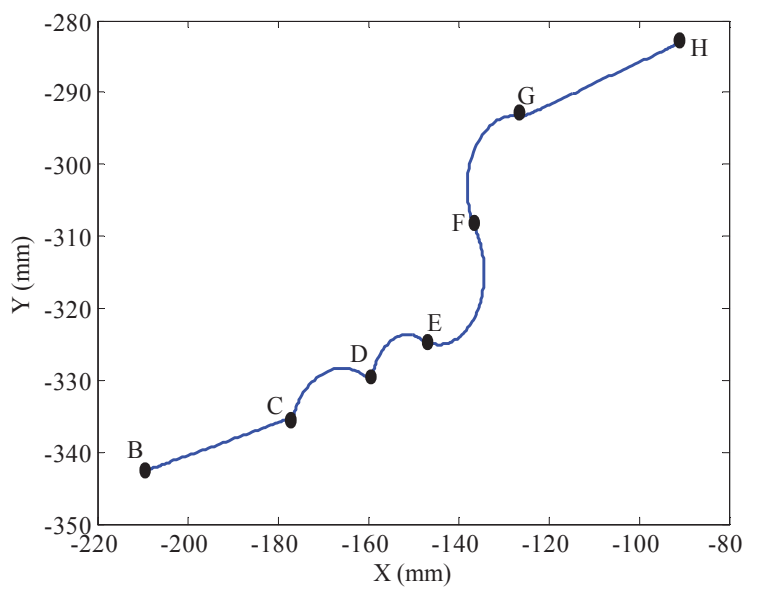

Tool center path

Fig. 6: Simulating machining of a work piece with a tool diameter $12 \mathrm{~mm}$

Fig. 7 shows respectively the experimental and theoretical feed rate for an error value equal to $0.3 \mathrm{~mm}$ (a) and the histogram of actual, simulated and calculated time by the CAM software (b).
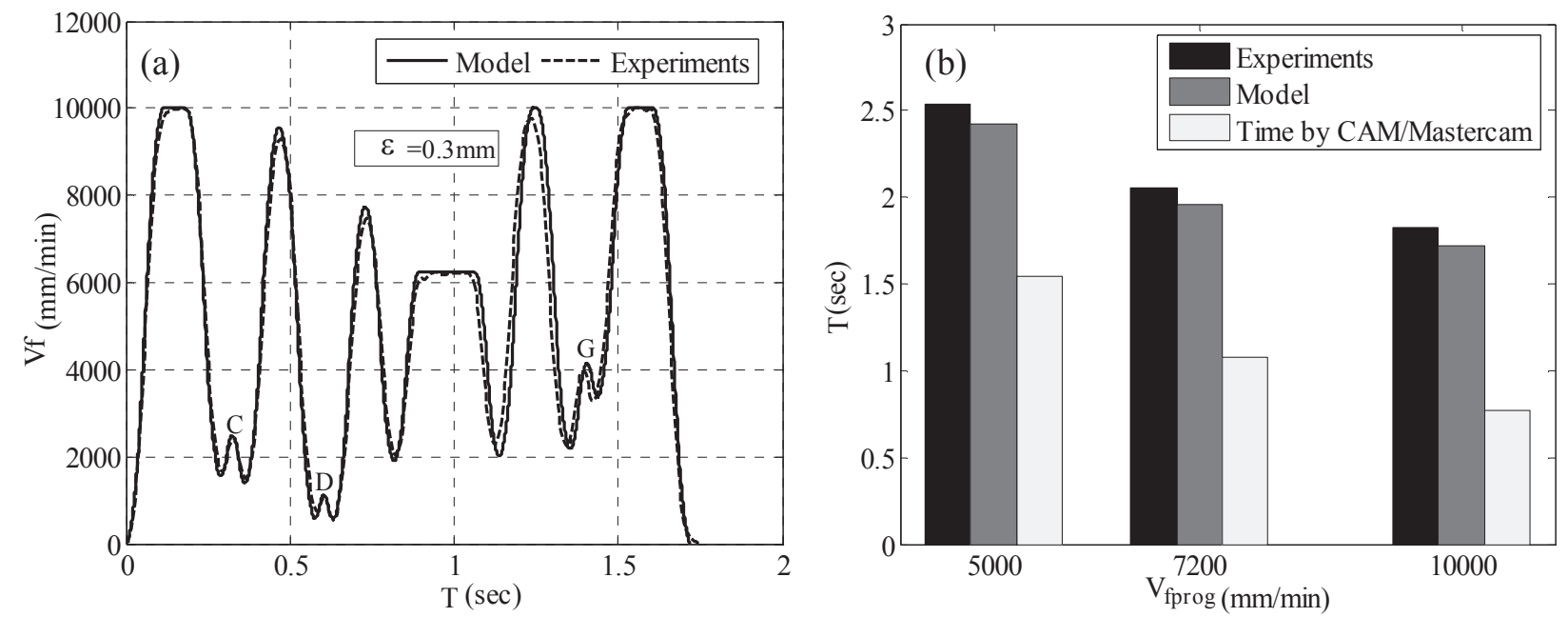

Fig. 7: Profiles of the theoretical and experimental feed rate (a) and cycle time for different programmed feed rate $(b)$

These results show a good correlation between experimental and theoretical model of this work. It is noted that the programmed feed rate will not be achieved only for a certain percentage of the total length of the tool path. This percentage depends on the length of the elementary interpolation, the type of discontinuity and the programmed feed rate value. As clearly seen on Fig. 7.b, the time calculated by the CAM software (length / programmed feed rate) underestimates the real machining time. It can be concluded that the importance of this shift should be taken into account during the establishment of the estimated cost. In a HSM context, the actual machining time is particularly dependent on slowdowns axis movement on the paths followed. 


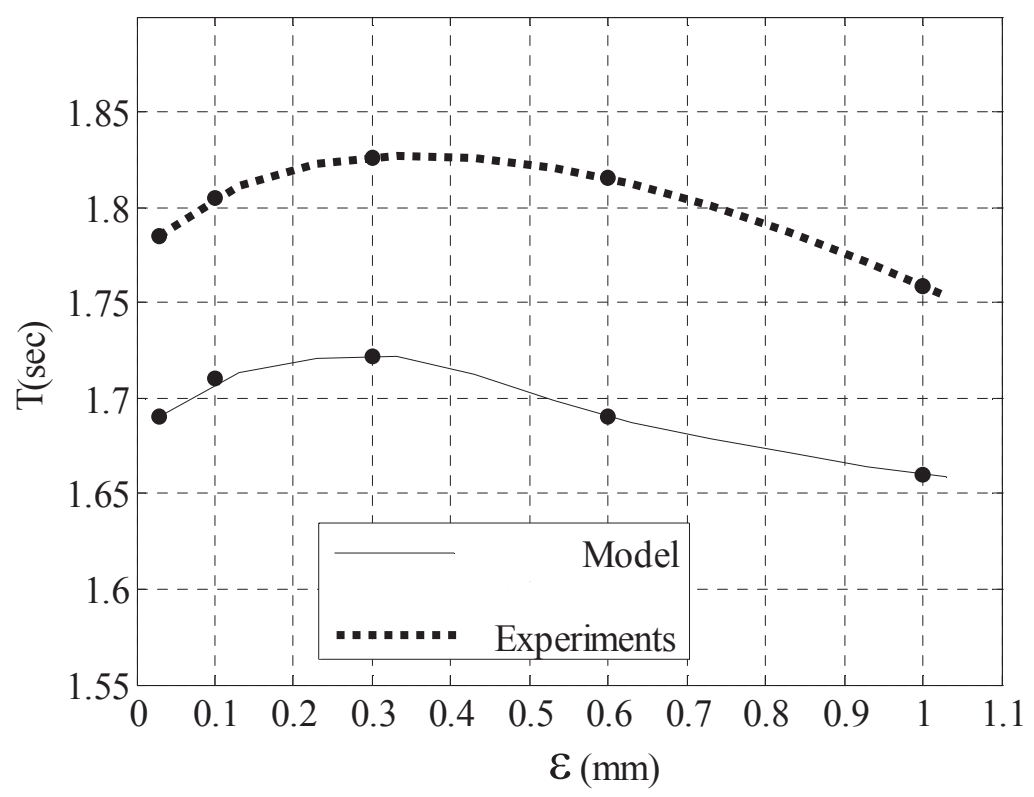

Fig. 8: The impact of the imposed error on the cycle time

Fig. 8 shows the evolution of cycle time depending on the imposed error value between the actual and programmed trajectory. It allows, for example, defining the optimal error value. We note that when the error values increase, the connection radius increases too and subsequently the feed rate of transition. However, this gain in speed does not lead to decrease of the total cycle time. Thus, it is necessary to select the optimal error value. In addition, a small increase in the error value has not a significant influence on reducing the cycle time. This increase will be significant only when the error value $\varepsilon$ exceeds $0.3 \mathrm{~mm}$.

Fig. 8 shows also that the maximum error between theoretical and experimental results is $5 \%$ and this, in a quasi-constant way for all tests.

\section{Conclusion}

This work presents a theoretical and experimental study of the evolution of the feed rate in HSM for a tool path discretized into linear and circular interpolation. The study has developed a model describing the behaviour of the axes of machine for any kind of trajectory. In addition, the model developed allows determining the impact of the imposed error value on the cycle time. The theoretical study was elaborated in two parts. The first part is devoted to the modeling of the feed rate with continuity in tangency. However, the second one aims at geometric modeling of continuities in tangency: it consists in calculating the radius between linear and circular interpolations in different combinations with respecting the tolerance imposed by the method office $(\varepsilon)$.

The experimental study is based on elementary tests to determine the influence of the tool path geometry on the feed rate evolution as well as the impact of the imposed error value. This approach can be generalized to any machining strategy. The comparison between the results obtained by the theoretical model and experimental study demonstrates a maximum error of $5 \%$.

The next step is to develop a calculation interface in order to automate the determination process of the evolution of the feed rate for an imposed error and the estimation of cycle time and production cost. This allows the industry to minimize the reflection time of operators before the establishment of the estimated cost. 


\section{References}

[1] P. Krajnik and J. Kopa: Modern machining of die and mold tools, Journal of Materials Processing Technology , 157-158 (2004), pp. 543-552,

[2] H. Siller, C. A. Rodriguez and H. Ahuett: Cycle time prediction in high-speed milling operations forsculptured surface finishing, Journal of Materials Processing Technology, 174 (2006), 355-362,

[3] M. Moneral and C. A. Rodriguez: Influence of tool path strategy on the cycle time of highspeed milling, Computer- Aided Design, 35 (2003), 395-401.

[4] L. Tapie, B.K. Mawussi and B. Anselmetti: Circular tests for HSM machine tools: Bore machining application, International Journal of Machine Tools \& Manufacture, 47 (2007), 805819.

[5] X. Pessoles, J.M. Redonnet, S. Segonds and M. Mousseigne: Aide Modelling and optimising the passage of tangency discontinuities in NC linear paths, The International Journal of Advanced Manufacturing Technology, 58(2012):631-642.

[6] A. Dugas: Simulation d'usinage de formes complexes, Phd thesis, IRCCYN, Ecole Centrale Nantes (2002).

[7] V. Pateloup: Amélioration du comportement cinématique des machines outils UGV Application au calcul de trajets d'évidement de poches, Phd thesis, Blaise Pascal - Clermont II University (2005).

[8] K.Erkorkmaz and Y. Altintas: High speed CNC system design. Part I : jerk limited trajectory generation and quintic spline interpolation, International Journal of Machine Tools \& Manufacture, 41(2001), 1323-1345

[9] B. Gassara , M. Baili , G. Dessein , M. Hbaieb and W. Bouzid Saï: Feed rate modeling in circular-circular interpolation discontinuity for high-speed milling, The International Journal of Advanced Manufacturing Technology , (2012) DOI 10.1007/s00170-012-4284-z

[10] Sinumerik 840Dsl/840Disl/840D/840Di/810D Manuel de programmation Notions de base, 11/2006, www.automation.siemens.com/doconweb/ 